\section{Mobilidade social, valores morais $e$ segregação espacial}

SCALON, Celi; ARAÚJO, Clara; MARQUES, Eduardo \& OLIVEIRA, Maria Aparecida. Ensaios de estratificação. Belo Horizonte, Argumentum, 2009. 152 páginas.

\section{Marcelo Medeiros}

Marcada pelo rigor metodológico e pela relevância dos objetos que estuda, a análise da estratificação social é uma das áreas mais tradicionais da sociologia. Incorporando novas teorias, técnicas mais precisas e aplicando-as a dados atuais, a área se renova continuamente no Brasil e ajuda a entender melhor por que nossa sociedade é tão desigual e o que pode ser feito para mudar essa situação. O livro Ensaios de estratificação é uma contribuição de destaque em quatro temas reconhecidamente importantes nessa área: mobilidade intergeracional, opinião pública sobre desigualdade de renda e justiça, valores morais relacionados com papéis de gênero e segregação espacial.

O livro reúne cinco estudos de Celi Scalon, alguns deles escritos em colaboração com Clara Araújo, Eduardo Marques e Maria Aparecida Oliveira. Seu objetivo principal é fazer uma análise empírica da estratificação no Brasil e de como ela é reconhecida, justificada e se distribui espacialmente. Para isso os estudos baseiam-se em dados de cobertura ora nacional, ora referente às metrópoles do Rio de Janeiro e São Paulo, e utilizam dois esquema de estratificação internacionalmente aceitos, por títulos ocupacionais e por rendimentos.

O primeiro estudo, escrito no início dos anos 2000, examina a mobilidade estrutural no Brasil ocorrida entre 1988 e 1996. Aponta um aumento razoável na mobilidade intergeracional de homens e mulheres, em geral devido à migração para áreas urbanas. A maior parte dessa mobilidade, no entanto, foi de curta distância e não alterou substantivamente o padrão de estratificação social no país, tal como se vem observando já há algumas décadas. A análise da mobilidade intrageracional mostra que a rigidez do mercado de trabalho continua elevada. Os aumentos de mobilidade entre o início e o fim da carreira dos trabalhadores, quando ocorrem, evidenciam um quadro nada positivo: as chances de os homens e, particularmente, as mulheres observarem uma piora em suas carreiras profissionais aumentaram na década de 1990 , ao passo que a possibilidade de progresso permaneceu reduzida. Os estratos de elite, porém, são capazes de preservar sua posição ao longo do tempo.

Em termos gerais, conclui Scalon, nenhuma mudança abrupta na desigualdade e nos padrōes de mobilidade inter e intrageracional no Brasil foi observada entre 1988 e 1996, sinal do fracasso do ideal desenvolvimentista da década de 1950, no qual o crescimento econômico ampliaria a classe média, reduziria desigualdades e transformaria o formato da estrutura social de uma pirâmide de base larga para um losango. O país continua muito desigual, e as pessoas têm chances limitadas de progredir em suas trajetórias profissionais.

Diante desses resultados, cabe perguntar como a população do país reconhece e reage à tamanha desigualdade e imobilidade. Este é o objeto do segundo estudo, que se baseia em dados do levantamento do International Social Survey Program ISSP de 2000, comparando as opiniōes da elite, formada pelo décimo mais rico da população, e do restante da população. Trata-se de uma pergunta crucial, uma vez que as decisóes dos indivíduos quanto à educação, à inserção ocupacional e mesmo a escolhas políticas são diretamente afetadas por suas opiniōes quanto ao nível de desigualdade do mercado de trabalho, às chances de mobilidade dentro dessa estrutura desigual e à justiça dessa situação.

Elite e povo concordam que as desigualdades de renda no Brasil são muito grandes e vêem a estrutura social do país como uma pirâmide de base larga, mas não exatamente do mesmo modo. A elite tende a aceitar uma desigualdade salarial maior e é mais cética quanto às possibilidades de progresso individual por meio do esforço pessoal e qualificação profissional. As diferenças entre elite e povo emergem mais claramente quando se pergunta quais são os principais problemas sociais do país e que soluções devem ser buscadas para a desigualdade. Desemprego e pobreza são as maiores preocupações do povo, ao passo que da elite, aparecem desigualdade de renda, corrupção e educação. Reforma agrária 
e participação nos lucros das empresas constituem soluções mais presentes no povo e melhoras nos serviços públicos e controle de população aparecem com mais freqüência como soluçôes vislumbradas pela elite.

Elite e povo acham que a estrutura social está longe daquilo que deveria ser - na opiniāo de mais da metade da população, um losango que expressa uma pequena classe baixa, uma grande classe média e uma reduzida elite. Todos julgam que a promoção da igualdade cabe ao governo e priorizam a provisão de serviços públicos, mas muito poucos aceitam elevações de tributos que permitiriam financiá-los, o que leva Scalon à conclusão de que não parece haver saída possível para o impasse da desigualdade no Brasil.

No terceiro estudo Celi Scalon e Clara Araújo analisam resultados de um levantamento de cobertura nacional do ISSP feito em 2003 para pesquisar valores relacionados com a conciliação entre trabalho doméstico e trabalho pago. Seu objetivo é verificar se as relações de gênero vêm se tornando mais igualitárias como conseqüência da entrada maciça das mulheres no mercado de trabalho nas últimas décadas.

As respostas do levantamento revelam que a desigualdade na carga de trabalho doméstico, muito maior entre as mulheres, é aceita como natural pelos adultos de ambos os sexos. Valores igualitários surgem à medida que a religiosidade diminui e a escolaridade dos entrevistados aumenta e são mais fortes entre as mulheres ocupadas em trabalho pago, mas isto não é suficiente para alterar a divisão objetiva de tempo empenhado em trabalho doméstico não-pago. Em função disso, as autoras afirmam que o trabalho de reprodução da vida cotidiana é um dos aspectos menos permeáveis à mudança da sociedade contemporânea.

Os dois estudos finais tratam de um tema de importância crescente nas análises de estratificação, qual seja, a relação entre desigualdades sociais e segregação espacial. Informações censitárias mostram que nas metrópoles do Rio de Janeiro e São Paulo a configuração do espaço urbano está fortemente associada à estrutura ocupacional desses locais e que, apesar da geografia distinta, os padrões de dispersão urbana das classes sociais é muito semelhante nas duas metrópoles. Celi Scalon, Eduardo Marques e Maria Aparecida Oliveira constatam que as duas possuem estruturas ocupacionais similares e são marcadas por forte segregação espacial. Em ambas a topologia social sobrepõe-se à territorial e a distância social entre as classes reflete-se também em distância espacial.

Ao contrário do que previam certas teorias de urbanização, a segregação espacial em São Paulo não parece ser afetada por fenômenos como globalização, reestruturação produtiva e suas conseqüências na atividade econômica. Apesar das substantivas mudanças econômicas ocorridas ao longo da déca$\mathrm{da}$, houve pouca mudança na estrutura ocupacional paulistana e, mesmo onde essa mudança foi mais notável, não houve polarização da estrutura social, o que os autores caracterizam como "a inabalável segurança dos processos de reprodução de desigualdades e sua capacidade de absorver e sobreviver a ondas de transformação da sociedade” (p.146).

Permeando todos os artigos do livro, há uma perspectiva teórica comum na sociologia da estratificação social: a de que as posiçôes dos indivíduos na hierarquia de classes é determinada por uma estrutura rígida e de que há pouco que os indivíduos ou mesmo agentes coletivos possam fazer para alterar este quadro. Herança do estruturalismo e do funcionalismo que durante muito tempo dominaram a disciplina, esse pessimismo reflete-se no enfoque dado aos estudos, fazendo com que as análises se concentrem em evidenciar a rigidez da sociedade em vez de explorar os determinantes da mobilidade em busca de elementos que poderiam ser modificados para promover a ascensão social dos indivíduos.

Se de um lado a rigidez da sociedade é um fato, de outro, do ponto de vista da pesquisa aplicada engajada em um projeto igualitarista, a rigidez completa esvazia a relevância da pesquisa no tema. Para os formuladores de política pública, por exemplo, um problema sem qualquer possibilidade de solução pragmática é um problema que não interessa. Isto, porém, não diminui a importância do livro, apenas inibe a expectativa ingênua de que pequenas ações serão capazes de causar grandes mudanças na sociedade. Para este tipo de leitor, os estudos reunidos devem ser vistos sob dois ângulos. Primeiro, 
como uma obra que apresenta os desafios a serem enfrentados pelas políticas de educação, mercado de trabalho, igualdade de gênero e planejamento urbano; segundo, como ponto de partida para o exame das causas da rigidez e para a formulação de projetos no sentido de eliminá-la.

O livro interessa a uma comunidade ampla de estudiosos da desigualdade, cientistas políticos e urbanistas. Suas partes mais técnicas são seguidas por interpretações acessíveis dos resultados, o que torna sua leitura possível mesmo por um público não especializado. Como se trata de uma compilação de artigos isolados, falta na obra um eixo condutor claro que vincule um estudo a outro, bem como um capítulo de conclusão capaz de abarcar e dar um sentido mais nítido aos achados, tarefa que é deixada ao leitor. Em Ensaios de estratificação, artigos que foram publicados em revistas nacionais importantes e outros inéditos estão convenientemente reunidos em um volume único.

\section{MARCELO MEDEIROS é professor do departamento de Sociologia da Universidade de Brasília. E-mail: <medeiros@igualdade.org.br>.}

\section{A gênese da juventude mal escolarizada}

RIBEIRO, Luiz Cesar Queiróz \& KAZTMAN, Rubem (orgs.). A cidade contra a escola? Segregação urbana e desigualdades educacionais em grandes cidades da América Latina. Rio de Janeiro/Montevidéu, Letra Capital/Faperj/Ippes, 2008. 367 páginas.

\section{Rodrigo Rosistolato}

Trabalhos coletivos são um desafio para as ciências sociais. Considerando sua natureza préparadigmática, no sentido proposto por $\mathrm{Kuhn}^{1}$, a convivência, em alguns casos conflituosa, de opções teórico-metodológicas é talvez a maior riqueza deste campo do saber, mas também seu principal dilema. Como transitar da compreensão particular para a generalização? Como generalizar sem ignorar as especificidades de contextos socioculturais particulares? Estas questões são típicas de ciências em que o objeto não existe senão quando construído por conceitos e filiações a tradições de pensamento.

A educação já foi apresentada como um objeto rejeitado na sociologia, ${ }^{2}$ porque associada a engenharias sociais. Sabe-se, no entanto, que o desejo de verdade, alardeado pelas raízes positivistas das ciências sociais, tem perdido força devido às sucessivas críticas às generalizações excessivas, e alguns de seus possíveis efeitos quando transformadas em argumentos para defesa de intervenções sociais. Mas, ao mesmo tempo, pairam expectativas de compreensão e, quem sabe, contribuição crítica para a resolução dos dilemas da ordem social pressuposta pela modernidade.

Como superar tal dilema? Como generalizar descobertas de pesquisa sem desconsiderar especificidades locais? Como trabalhar conceitualmente sem desvalorizar a visão dos atores sociais envolvidos diretamente nos processos analisados? O livro $A$ cidade contra a escola? apresenta possíveis caminhos e estratégias metodológicas para o enfrentamento destas questôes.

Os autores apresentam a escola como uma instituição moderna, organizada por expectativas de promoção de igualdade e equidade por meio da distribuição de um tipo específico de saber, discutido e oferecido coletivamente. Mas apontam que a construção de certo grau de homogeneidade cul- 
tural pelo oferecimento de saberes racionalmente organizados e distribuídos não é possível sem o diálogo com elementos culturais transmitidos por processos de reprodução social independentes da escola. O pertencimento a classes sociais tradicionalmente afastadas da cultura escolar, a grupos que desvalorizam a cultura escrita como organizadora das relaçôes sociais, a populaçôes segregadas na organização social das cidades cria obstáculos à distribuição igualitária do saber escolar.

O livro examina possíveis relações entre segregação residencial e desigualdade de chances de escolarização de crianças e jovens na América Latina. Trata-se de um vigoroso trabalho coletivo, singular nas hipóteses e comparativo por definiçãa. As investigaçōes foram realizadas em três instituições de pesquisa: a Universidade do Texas, a Universidade Católica do Uruguai e a Universidade Federal do Rio de Janeiro. A hipótese principal é de que a crise do modelo de substituição de importações e a inserção das economias latino-americanas na globalização acabaram por enfraquecer mecanismos amortecedores das desigualdades sociais. A concentração territorial da pobreza - um dos resultados desta mudança - é apresentada como fenômeno desencadeador de processos de produção de desigualdades e exacerbação de tendências à fragmentação do tecido social. Este fenômeno geral influencia diversos aspectos da sociabilidade contemporânea em todos os países onde a pesquisa tem sido realizada.

Os autores entendem que a concentração territorial dos segmentos vulneráveis se transforma em segregação residencial, causando isolamento físico, sociocultural, de direitos cívicos e políticos inerentes à condição urbana. Em alguns contextos a distância territorial combina-se com distância social, fazendo com que a sociabilidade se empobreça e deixe de propiciar interaçóes e trocas próprias do fenômeno urbano. Mesmo no caso do Rio de Janeiro, com sua distribuição territorial peculiar, há distâncias sociais significativas entre grupos de pessoas que ocupam espaços fronteiriços. $\mathrm{O}$ isolamento é apresentado como fenômeno que pode tomar a forma de distância sociocultural, proporcionando mecanismos de polarização social e induzindo práticas de resistência à violência simbólica de que são objeto os grupos estigmatizados.
O livro é dedicado, especificamente, ao debate sobre a "relação entre segregação residencial e desigualdades de chances de escolarização de crianças e jovens em cidades da América Latina” (p. 17). A pergunta que subjaz ao texto é: "em que medida a forma pelas quais as classes sociais se distribuem no território das grandes cidades facilita ou bloqueia o avanço da coesão social sobre as bases da equidade?" (p. 17). Os autores priorizam o exame dos efeitos do contexto social e da sociabilidade vigente em bairros populares de grandes cidades sobre $o$ desempenho educativo de crianças e adolescentes. Entendem que a análise dos efeitos de segregação residencial sobre desempenhos escolares não se justifica apenas no contexto da América Latina, por isso se propõem a aprofundar o conhecimento sobre o fenômeno, apresentado como universal.

$\mathrm{O}$ entendimento de que o combate aos efeitos da segregação urbana deve ser incorporado ao enfrentamento da pobreza e das desigualdades sociais perpassa todo o trabalho. Existe, inclusive, uma preocupação com a construção de políticas públicas que desatrelem o desempenho escolar das desigualdades dos contextos econômicos de origem. $\mathrm{Na}$ apresentação, os organizadores afirmam que "é preciso lutar contra as desigualdades de origem, que já definem a posição e a trajetória dos indivíduos na sociedade" (p. 18).

O livro aponta questóes fundamentais para as reflexões da sociologia da educação. Em alguns contextos, a escola e a família competem com outras formas de integração. O pertencimento a um determinado bairro pode, inclusive, criar o que os autores classificam como habitus negativo relacionado com a escola. As crianças teriam maior dificuldade de separar razão e emoção, descontrole sobre o próprio corpo, dificuldades de abstração e insegurança ontológica causada pela exposição à violência. Este habitus negativo contribuiria para a consolidação de um tipo de "profecia que se cumpre". Estudantes oriundos de bairros segregados chegariam à escola orientados pela crença de que aquele espaço não seria delas, ou para elas. Em conseqüência, resistiriam ao espaço por meio do silêncio, da violência ou da ausência de aprendizado.

A cidade contra a escola? é composto por onze artigos, dos quais seis são escritos em parcerias, além 
da introdução redigida pelos organizadores. Ana Lourdes Suárez e Fernando Groisman discutem a segregação residencial e as conquistas educacionais na Argentina; Haroldo da Gama Torres, Renata Mirandola Bichir, Sandra Gomes e Thaís Regina Pavez Carpim analisam a educação na periferia de São Paulo; Fátima Alves, Francisco Creso Junqueira Franco Júnior e Luiz César de Queiroz Ribeiro pensam a segregação residencial e as desigualdades escolares no Rio de Janeiro; José Francisco Soares, José Irineu Rangel Rigotti e Luciana Teixeira de Andrade enfocam as desigualdades socioespaciais e o efeito das escolas públicas de Belo Horizonte; Carolina Flores apresenta a segregação residencial e os resultados educacionais na cidade de Santiago do Chile; Gonzalo Saraví analisa a segregação urbana, a sociabilidade e a escola na cidade do México como uma coexistência entre mundos isolados; Patrício Solis analisa os efeitos do nível socioeconômico da vizinhança na continuidade escolar entre o ensino médio e o pré-universitário no México; Alejandro Retamoso e Ruben Kaztman discutem os desafios da educação a partir de processos de segregação urbana; Robert $\mathrm{H}$. Wilson pensa a integração da forma urbana e a política pública; Camilo Arriagada Luco e Yael Korol Engel salientam os desafios às políticas educacionais que surgem com as novas tendências à segregação urbana e Nestor López discute o caráter territorial dos processos educacionais nas cidades.

Os textos apresentam resultados de pesquisas desenvolvidas na Argentina, na cidade de São Paulo, na cidade do Rio de Janeiro, em Belo Horizonte, em Santiago do Chile e na cidade do México. Discutem algumas temáticas consolidadas nos estudos sociológicos da educação, como o "efeito-escola", e inserem um elemento novo que pode contribuir significativamente para as análises realizadas pela sociologia da educação em interface com a sociologia urbana e o planejamento das cidades. Tratase do "efeito de vizinhança" - a tese propõe que a organização da cidade seria a expressão máxima da distribuição não-igualitária de bens e serviços sociais, contribuindo para a manutenção das mesmas relações sociais que a produziram.

$\mathrm{O}$ modelo de análise que orienta o projeto parte do entendimento de que fenômenos sociais podem ser explicados a partir de múltiplas relações de causa e efeito. $\mathrm{O}$ acontecimento analisado seria o efeito de causas diversas, que poderiam ser mapeadas e utilizadas para explicar o fenômeno em suas múltiplas determinações. Há, na proposta, a indicação de que as motivaçóes, as escolhas e os comportamentos individuais dialogam com contextos onde pessoas com certas propriedades comuns ou semelhantes se encontram. As relações sociais desenvolvidas no espaço de moradia não são resultado ou simples consequiência da composição social dos bairros, mas consolidam-se como uma variável importante para a explicação de comportamentos sociais. Existe um duplo movimento em que constrangimentos estruturais e escolhas individuais dialogam e produzem resultados que só podem ser compreendidos levando em consideração todas as dinâmicas envolvidas nesse processo.

Embora identifique as dificuldades enfrentadas por crianças oriundas de meios segregados para a incorporação da cultura escolar, o livro não descaracteriza a escola como espaço de produção e distribuição de saber. Trata-se de uma contribuição importante para o debate sobre a construção dos sistemas escolares e sua relação com a organização social do espaço em grandes metrópoles. $\mathrm{O}$ texto indica que a escola compete com outras vias de integração social, como o trabalho ou até mesmo a opção pela constituição de família.

Pensando especificamente o caso brasileiro, as análises apresentadas indicam que trajetórias de escolarização em escolas públicas e periféricas impedem ou atrapalham a consolidação dos saberes considerados básicos. Dessa forma, estudantes que concluem a educação básica neste contexto não estão aptos a dialogar em igualdade com estudantes que trilharam seus percursos escolares em escolas centrais e particulares. Considerando que no Brasil os vestibulares para ingresso no ensino público superior - exceção feita às universidades que utilizam algum tipo de sistema de cotas - são disputados por todos os estudantes egressos do ensino médio, seja público ou privado, seja cursado em escolas centrais ou periféricas, é possível pensar que estudantes mais pobres, moradores das periferias urbanas, formados por escolas públicas, que não optassem por cotas estariam em desvantagem em face do vestibu- 
lar. Tenho trabalhado a partir desta hipótese, mas pensando especificamente nas estratégias utilizadas por estudantes pobres que decidem se organizar em movimentos sociais para se prepararem para o vestibular.

Existem, no Rio de Janeiro e em outros estados brasileiros, um conjunto de movimentos populares organizados por e para jovens pobres que desejam dar seqüência às suas carreiras estudantis. São cursos de pré-vestibular comunitários ou "alternativos", que oferecem formação complementar para que os estudantes possam competir nos vestibulares mais disputados. Minha pesquisa analisa as expectativas relacionadas com a educação superior presentes nestes espaços de ensino. Está em fase inicial, mas é possível perceber algumas regularidades no discurso dos estudantes. Eles culpam suas escolas de origem por não terem oferecido os conteúdos necessários para o vestibular, mas também assumem parte da culpa quando constroem suas memórias escolares e identificam situações que os permitiam experimentar o ambiente escolar sem, efetivamente, estudar.

Os dados iniciais permitem propor, a título de hipótese, que os pré-vestibulares são espaços de organização das memórias escolares e construção de novos sentidos associados à possibilidade de incorporação dos saberes escolares. Essas observações indicam a inadequação das escolas às necessidades dos jovens, mas também apontam as possibilidades de apropriação dos saberes oferecidos pela escola em um momento posterior à escolarização propriamente dita. Parece evidente que uma escola mais eficaz facilitaria o percurso dos jovens em direção ao ensino superior, mas é necessário dizer que, mesmo entre parcelas menos beneficiadas por escolas de qualidade, a escolarização ainda ocupa lugar central como orientadora de suas ações relacionadas com expectativas de mobilidade.

Os jovens freqüientadores de cursos de pré-vestibular "alternativos" são um dos frutos da precariedade da formação escolar oferecida em escolas públicas e periféricas no Brasil. As análises presentes em $A$ cidade contra a escola? permitem interpretar a gênese desta situação escolar. É claro que nem todos os estudantes formados em boas escolas podem abdicar dos cursos de pré-vestibular, mas as distâncias entre uns e outros se apresentam nas opções por carreiras de maior ou menor prestígio, e nos sucessivos fracassos enfrentados por aqueles que em vez de aperfeiçoar o aprendido têm que aprender exatamente no momento em que saíram da escola.

\section{Notas}

1 T. S. Kuhn, A estrutura das revoluções cientificas, São Paulo, Perspectiva, 1998.

2 L. A. Cunha, "A educação na sociologia: um objeto rejeitado?”. Cadernos Cedes: Sociologia da Educação: Diálogo ou Ruptura, São Paulo, Papirus, 1992.

\section{RODRIGO ROSISTOLATO é professor adjunto de sociologia da educação na Universidade Federal do Rio de Janeiro (UFRJ - campus Macaé). E-mail: <rosistolato@yahoo.com.br>.}




\section{As Ciências Sociais a Serviço da Vida}

ZIMERMAN, Artur. Peguem a foice e vamos à luta: determinantes agrários da guerra civil. São Paulo, Humanitas, 2008. 224 páginas.

\section{Pedro Neiva}

O livro de Artur Zimerman é fruto de sua tese de doutorado, defendida na Faculdade de Filosofia, Letras e Ciências Humanas da USP em dezembro de 2006. Ele busca identificar os elementos sociais e políticos determinantes das guerras civis que aconteceram no mundo entre os anos de 1969 e 1997 , período em que houve uma grande concentração delas. Mais especificamente, o autor avalia até que ponto fatores agrários motivam a eclosão dessas guerras, procurando identificar o impacto que variáveis como densidade demográfica, concentração e produtividade da terra e números de trabalhadores "sem-terra" e de pequenos proprietários exercem sobre a ocorrência desse tipo de conflito. Embora motive uma boa discussão teórica, o livro destacase pela riqueza empírica e pela metodologia utilizada, a qual será o alvo principal dos comentários que apresento.

A obra foi estruturada em seis partes: introdução, quatro capítulos e conclusão. No Capítulo 1, o autor apresenta uma cuidadosa definição de guerra civil, suas diferentes categorias e alguns detalhes sobre os três tipos considerados, a saber: revolução, secessão e internacionalizada. Nesse capítulo, há ainda uma breve discussão sobre a "teoria de guerra civil", que se mostra inacabada e ainda em processo de elaboração. O capítulo apresenta também a forma criteriosa com que o autor lida com seu banco de dados, além de tecer diversas considerações sobre a melhor maneira de classificar e conceituar uma guerra civil. No período estudado, o autor identificou 69 eclosóes desse tipo de conflito em cinqüenta países, considerando aqueles que tinham população acima de 1 milhão de habitantes no ano de 1970.

No Capítulo 2, Zimerman aborda o que chama de "determinantes consagrados" de guerra civil. Trata-se das condicionantes estruturais freqüentemente utilizadas pela literatura para explicar a eclo- são de uma guerra civil, as quais envolvem fatores econômicos, históricos, de identidade, políticos, geográficos e regionais. Entre outras, variáveis como renda per capita, ajuda internacional, dependência de recursos naturais, diversidade étnica e religiosa, regime político, repressão governamental, área montanhosa e área florestal são utilizadas como explicação para esse tipo de conflito. Algumas delas foram utilizadas pelo autor, mas apenas como variáveis de controle.

As variáveis mais importantes, testadas como fatores explicativos de guerra civil, são discutidas no Capítulo 3. Referem-se aos fatores agrários, que, até então, não vinham sendo tratados com a devida seriedade pela literatura, nacional ou internacional. A contribuição principal do livro encontra-se exatamente neste ponto: ele incorpora, de maneira adequada, as questóes agrárias na explicação para a eclosão de guerras civis. Trata-se realmente de uma medida fundamental, já que "uma guerra civil é, freqüentemente, de origem rural e camponesa", ainda que sejam conduzidas por lideranças que vivem nas zonas urbanas. As rebelióes que levam à guerra civil, segundo Zimerman, costumam ocorrer em zonas rurais, longe dos grandes centros, onde o controle do Estado é mais fácil e eficaz.

Para reforçar sua opção de incluir as variáveis agrárias em um modelo explicativo de guerra civil, o autor argumenta que a proporção da população rural e a taxa de ocupação no setor agrícola são maiores nos países que a experimentaram. $\mathrm{Na}$ sua visão, as questões agrárias ajudam a explicar, por exemplo, as guerrilhas recentes na América Latina, mais especificamente em Cuba, Venezuela, Guatemala, Colômbia, Peru, Nicarágua e El Salvador. Segundo ele, tais variáveis contribuem também para explicar diversos conflitos na Ásia e na África.

Para uma avaliação mais segura, Zimerman lança mão, no Capítulo 4, de análise rigorosa e sistemática, utilizando modelos de regressão logística binária, tendo a eclosão de guerras civis como variável dependente. Em linhas gerais, conclui que a instabilidade política, o número de agricultores "sem-terra" e de pequenos proprietários, o tamanho da população rural e a baixa produtividade rural apresentam-se como as variáveis mais importantes para explicação do fenômeno em questão. Ademais, 
variáveis como renda per capita e concentração da terra não se mostraram relevantes, contrariando as expectativas. $\mathrm{O}$ autor desconfia que tal resultado se deve ao fato de os dados disponíveis não serem satisfatórios, em virtude do sigilo que envolve as informações sobre o tamanho das propriedades rurais.

Em geral, creio que o livro goza de muitas qualidades. Em primeiro lugar, porque motiva uma boa discussão teórica, contribuindo efetivamente para o entendimento das guerras civis no mundo. Em segundo, porque se trata de um estudo comparativo, empiricamente rico, com um número de países relativamente grande, quando comparado com outros estudos de política comparada no Brasil. Não deixa de ser também um empreendimento corajoso, dada a dificuldade para obtenção desse tipo de dado e para a definição de critérios de categorização.

Além disso, trata-se de uma obra muito bem escrita, fluente, de leitura fácil e instigante. $\mathrm{O}$ autor expõe seus argumentos de forma clara, organizada e objetiva. O leitor pouco familiarizado com métodos quantitativos deverá ter um pouco mais de atenção, mas nada que o impeça de entender a discussão estabelecida no livro. Não é demais enfatizar o diferencial oferecido por Zimerman, ao considerar as variáveis de natureza agrária, que vinham sendo desprezadas em estudos do gênero.

Peguem a foice e vamos à luta destaca-se também pelo uso do instrumental metodológico. Confesso que, durante a leitura, em diversos momentos senti a necessidade de uma melhor especificação das técnicas utilizadas; porém, quase sempre, poucas linhas ou parágrafos depois, a resposta vinha de prontidão. Para aqueles que estão se familiarizando com análise de regressão, mais especificamente com regressão logística, o trabalho serve como um excelente exemplo de bom uso da técnica. Em função disso, sugiro ao autor que disponibilize seu banco de dados, tanto para os que quiserem replicar seus argumentos, como para aqueles que eventualmente queiram utilizá-lo como um interessante material de treinamento.

A despeito da qualidade de sua metodologia, pode-se questionar a adequabilidade da técnica utilizada para o tipo de dados que dispõe. As freqüências de sua variável dependente revelam um caso típico do que a literatura chama de "evento raro": em
3.706 observações, apenas 69 (1,89\%) são classificadas como início de guerra civil. Nessa situação, parece-me que uma regressão logística tradicional não seja a técnica mais apropriada, já que ela pode gerar coeficientes subestimados, mesmo em amostras com grande número de casos. ${ }^{1}$ A proposta do autor de utilizar uma análise de efeitos aleatórios não parece ser suficiente para resolver essa questão. Felizmente, King e Zeng apresentaram uma solução para o problema e disponibilizaram um software para implementá-la. ${ }^{2}$ Outra possibilidade seria utilizar a técnica conhecida como "regressão binomial negativa para inflação em zeros". ${ }^{3}$ Essa última divide o processo de estimação em duas partes, uma para os valores iguais a zero (quando o evento não ocorre) e outra para os valores diferentes de zero (o evento ocorre).

Ainda sob o ponto de vista metodológico, falta um manejo mais adequado do aspecto temporal. Penso que o trabalho teria ficado melhor se o autor tivesse tratado não apenas da eclosão, mas também da permanência das guerras civis. A técnica conhecida como "análise de sobrevivência", que envolve a modelagem do tempo em função do evento, permitiria resolver o problema das ocorrências que se repetem em um mesmo país. Além disso, proporcionaria a resposta para perguntas interessantes, tais como: Entre os países que entram em guerra, quais os que permanecem? E por quanto tempo? Que circunstâncias particulares aumentam ou diminuem a chance de que o conflito permaneça? Não foram essas, no entanto, as questóes que o autor se propôs a responder, conforme deixa claro desde o início do seu texto.

Caso haja uma segunda edição do livro, sugiro que se leve em consideração também a dimensão espacial. Isso porque a geografia física parece ter um papel importante na determinação das guerras civis. Além do continente em que elas se localizam, é importante observar o número de países fronteiriços, a existência de conflitos em cada um deles e a topografia da região. Fearon e Laitin, ${ }^{4}$ por exemplo, verificaram que terrenos montanhosos estavam associados com uma maior freqüência de guerra civil. Embora o autor reconheça parcialmente a relevância desse aspecto, ele não o inclui em nenhum de seus modelos explicativos. 
Peguem a foice e vamos à luta merece ser lido não só por cientistas sociais que se dedicam ao tema das guerras civis, mas também por todas as pessoas que se preocupam com os seus efeitos devastadores. E mais, ele merece ser traduzido, pois interessa a pesquisadores de outros países, onde o fenômeno é ainda mais ameaçador do que no Brasil. Quanto maior for o conhecimento dos cientistas sociais sobre esses eventos trágicos, que vitimaram $134 \mathrm{mi-}$ lhões de pessoas no século XX, maior pode ser sua colaboração no sentido de evitá-los.

\section{Notas}

1 G. King e L. Zeng, "Logistic regression in rare events data”. Political Analysis, 9 (137), 2001; “Explaining rare events in international relations", International Organization, 55: 693-715, 2003.

2 Disponível em < http://gking.harvard.edu/stats.shtml>.

3 J. Hilbe, Negative binomial regression, Nova York, Cambridge University Press, 2007.

4 J. Fearon e D. Laitin. "Ethnicity, insurgency, and civil war". American Political Science Review, 97: 75-90, 2003.

\section{PEDRO NEIVA é doutor em ciência política pelo Iuperj. \\ E-mail: <prneiva@gmail.com>.}

\section{Entre o local e o cosmopolita: a teoria política latino-americana}

AMADEO, Javier \& ARAÚJO, Cícero (orgs.). Teo ria política latino-americana. São Paulo, Hucitecl Fapesp, 2009. 388 páginas.

\section{Júlio César Casarin Barroso Silva}

Num movimento a que a consolidação da vida democrática em nosso país não é inteiramente alheia, ao longo dos últimos anos tem sido possível vislumbrar um crescente interesse editorial pela teoria política, a qual vem pouco a pouco conquistando ao menos uma parcela do espaço que lhe cabe na discussão dos temas públicos. Nesse processo, têm-se destacado algumas tradições do pensamento político, como o republicanismo e o liberalismo

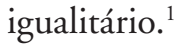

Nesse contexto, é bem-vinda a publicação de uma obra capaz de contribuir com a discussão teórica não só em nosso país como também em nosso subcontinente: Trata-se do volume Teoria politica latino-americana. O livro é o resultado das Jornadas Latino-Americanas de Teoria Política, encontro ocorrido em São Paulo em 2005 e organizado conjuntamente pelo Conselho Latino-Americano de Ciências Sociais e pelo Departamento de Ciência Política da USP. O encontro reuniu acadêmicos de diversificada origem nacional e estirpe ideológica, o que se traduz agora num livro que destila pluralismo ao longo dos dezenove artigos que o compõem.

Semelhante diversidade teórica foi agrupada em quatro eixos, correspondentes às quatro partes que estruturam a publicação: "A condição periférica no pensamento político", "Tradição republicana e teoria democrática na América Latina", "Sociedade civil, Estado e questôes de justiça” e, por último, "Em busca do fundamento ontológico do político", em cada uma das quais se enfrentam temas candentes da teoria política.

Por evidentes limitações de espaço físico, não serei capaz de oferecer aqui uma discussão detalhada de todos os artigos que integram o volume, até porque, como sói acontecer em se tratando de semelhante ecletismo, a qualidade e o interesse do temas abordados e dos artigos variam, não apenas 
em função dos autores mas também das preferências dos leitores. Optei por selecionar e destacar alguns dos textos mais representativos e instigantes da publicação, por meio dos quais espero oferecer uma visão panorâmica da obra.

O livro é inaugurado com um artigo do peruano Aníbal Quijano, que trata dos nós que o processo histórico de constituição da América Latina legou ao presente ("Dom Quixote e os moinhos de vento na América Latina”). A constituição do subcontinente latino-americano é também a constituição histórica de uma forma de poder, a colonialidade (sucedida pela globalidade), cuja persistência explica e causa determinadas obsessões e "fantasmas" (a imagem é de Quijano) latino-americanos, como o problema da identidade (da independência até fins do século XIX) e a ânsia pela modernidade (mais nítida a partir do século XX). $\mathrm{Na}$ constituição da colonialidade, a América Latina desempenha, por assim dizer, um papel privilegiado e fundacional, mas o faz na qualidade de pólo passivo. O problema da identidade é trazido pelo fato de que o ato pelo qual a América Latina é constituída como sujeito (a conquista) é o mesmo pelo qual ela se constitui como entidade subordinada. A colonização, dessa forma, constitui a periferia qua periferia e a insere no reino da modernidade e de suas promessas ao mesmo tempo em que institui as práticas que negam tais promessas. A modernidade, assim, na periferia, é a "criança que o tempo novo anuncia e nega" do verso de Drummond.

A subordinação da América Latina não se sustenta apenas no plano das relações econômicas, muito menos no âmbito exclusivo da força: apóiase também no plano intelectual. Nesse sentido é que o autor chama a atenção para o fato de ter sido a colonização latino-americana, como ato inaugural do novo padrão de poder colonial, o momento preciso da gênese do racismo. Quijano é bastante direto neste aspecto: se o colonialismo é uma instituição muito antiga, é apenas "com a colonização ibero-cristã das sociedades e populações da América" que se teria produzido "o conceito mental de raça” (p. 31). Não por acaso, é ao tempo do princípio da colonização americana que os certificados de "pureza" e de "limpeza" de sangue passaram a fazer parte da vida espanhola. "Tal certificado - à par- te de ser testemunho da primeira 'limpeza étnica' do período da modernidade ou colonial - pode ser como o mais imediato antecedente da idéia de raça, já que implica a ideologia de que as idéias religiosas, ou mais geralmente a cultura são transmitidas pelo 'sangue”, diz Quijano (p. 31).

Mas é a segunda parte da obra, "Tradição democrática e teoria republicana na América Latina” que merece o maior destaque nesta resenha, segundo meu juízo. Ali o mexicano Ambrosio Velasco Gómez oferece-nos "Relevância do republicanismo novo hispânico", primoroso artigo que, tomando o pretexto do debate espanhol sobre a legitimidade da guerra de conquista dos povos e terras americanos, no século XVI, faz valioso e raro panorama do republicanismo ibérico. No artigo, Gómez concentra-se em dois autores: Freis Alonso de la Veracruz e Bartolomeu de las Casas.

Como se sabe, a tradição republicana reconhece-se tributária de inúmeras fontes nacionais, temporais e autorais. Há divergências sobre os limites precisos dessa tradição e seu conteúdo normativo e teórico. Mas não serei demasiado polêmico afirmando que no centro do republicanismo está uma determinada concepção relativamente exigente de liberdade, entendida como ausência de dominação. ${ }^{2}$ Também podemos dizer que o republicanismo proclama-se tributário das experiências políticas da Antigüidade Clássica, da Florença e da Veneza Renascentistas e da República Holandesa, manifestando sua influência ainda durante a Guerra Civil Inglesa e as Revoluções Americana e Francesa. ${ }^{3}$ Entre os cânones republicanos, é comum que se incluam autores como Cícero, Maquiavel, Harrington, Milton, Rousseau e Thomas Jefferson. O que Gómez revela é o contraste entre o vigor histórico do pensamento republicano espanhol, capaz de figurar entre os cânones enumerados acima, e seu relativo esquecimento.

Traçando as origens do republicanismo ibérico podemos retroceder até Alonso de Castrillo (autor do Tratado da República, de 1521), continuando a genealogia intelectual com Francisco de Vitória, Domingo de Soto, chegando a seus discípulos Alonso de la Veracruz e Bartolomeu de las Casas, no Novo Mundo. Se Bartolomeu de las Casas é razoavelmente conhecido entre nós como um crítico 
da escravização dos indígenas e do "direito" de conquista, a base republicana sobre a qual foi montada sua argumentação é menos notada. SegundoVelasco Gómez, o republicanismo ibérico não se limitou a ser um pólo passivo de influência intelectual: Henri Gregoire, ideólogo da Revolução Francesa, manifestava grande admiração por las Casas e reconhecia a ascendência intelectual que o espanhol exercera sobre ele, Gregoire. Tampouco se tratava de um pensamento sem nenhuma correspondência na vida real: embora a Corte Espanhola não fosse nenhum modelo de autogoverno coletivo, havia experiências pontuais de participação cidadã desde os tempos de Afonso X, como as Cortes e as Juntas Cidadãs (p. 108).

A conquista do Novo Mundo apresentava o problema do "domínio justo" do soberano espanhol sobre os habitantes originais do continente. Ginés de Sepúlveda, defensor da legitimidade da conquista, afirmava que os povos originários eram bárbaros, característica que os tornava intrinsecamente incapazes de autogoverno. Antes de aspirar a isso, teriam de ser "civilizados" por meio da evangelização. Nestes termos, o problema antropológico da racionalidade dos indígenas adquiria precedência lógica sobre o da legitimidade da conquista, não podendo enfrentar-se este último sem passar-se pelo primeiro.

Os republicanos espanhóis tratavam assim de argumentar em favor do caráter plenamente racional dos nativos, evidenciando uma espécie multiculturalismo avant la lettre: os indígenas seriam racionais porque capazes de "reconhecer e aplicar a lei natural, a qual pode assumir múltiplas interpretaçôes segundo o sentido comum de cada povo" (p. 109). Uma vez que os indígenas eram plenamente racionais e conhecedores da lei natural, o domínio espanhol sobre eles precisaria passar pelos crivos republicanos de legitimidade. E um domínio legítimo, de acordo com esses critérios, é um domínio consentido pelo povo. Como tal autorização não fora dada pelos nativos ao soberano espanhol, o domínio europeu nas "Índias" carregava o fardo da suspeição de ser um domínio tirânico.

Gómez dedica atenção especial a Alonso de la Veracruz, personagem chegado à Nova Espanha em 1536, fundador da primeira biblioteca de filosofia do continente e professor da Real Universidade do México a partir de 1553. No dizer do autor do artigo, "Frei Alonso não veio só para ensinar, como também para aprender a língua e a forma de vida dos indígenas, especialmente a língua tarasca. Assim esforçou-se por compreendê-los e reconhecêlos como seres humanos com plena dignidade e como povos livres e civilizados" (pp. 110-111). Sua defesa dos indígenas pode ser encontrada principalmente na obra "Do domínio dos índios e da guerra justa”, da qual Gómez apresenta uma resenha em meio a seu artigo. "Do domínio..." compõe-se de onze dúvidas ou questóes, cada qual correspondendo a um capítulo em que se oferecem e se analisam argumentos a favor e contra o domínio espanhol na América. Alonso enfrenta ali questóes como o direito do soberano espanhol de impor tributos sobre os povos conquistados, a exigência do respaldo dos governados para o exercício do domínio, a obrigação do soberano de buscar o bem comum, a legitimidade das "Encomiendas"; ${ }^{4}$ o autor rebate os argumentos comumente levantados para justificar a conquista, como o da infidelidade dos índios, o pertencimento de jure do Novo Mundo ao Império Romano, os agravos dos índios aos espanhóis e sua oposição à prédica do evangelho, sua resistência a abraçar a fé, seus pecados contra naturam e seu suposto atraso mental e demência (p. 113). Alonso posiciona-se com clareza com relação à grande questão em disputa, concluindo que Carlos V não tinha domínio legítimo sobre os índios (p. 113), não podendo "licitamente arrebatar estes seus [dos índios] campos e haveres e dá-los a outros contra sua vontade" (Alonso apud Gómez, p. 113). Ao enfrentar questōes de ordem mais localizada, rebate a tese de que a guerra de conquista se justificava pelos "pecados" dos nativos: se assim fosse, o Papa também teria de guerrear contra os europeus. Ao rejeitar o argumento de que a infidelidade religiosa dos índios justificava sua perda de terras e de autogoverno, recorre a um raciocínio abertamente anticonfessional, separando o âmbito da fé do âmbito civil e político: "A fé, que é direito divino, não tira nem põe domínio que é de direito das gentes [...] o domínio desses indígenas em tempos de sua infidelidade era justo e legítimo" (Idem, ibidem). Já a acusação de "demência" feita aos nativos é afastada 
com base na capacidade de auto-organização política dos mesmos: "têm magistrados, um governo apropriado e os ordenamentos mais convenientes, e antes tinham governo e regime não só monárquico, senão aristocrático, como também suas leis; e castigavam os malfeitores, como também premiavam magnificamente àqueles que haviam merecido o bem da república” (Idem, p. 114).

Ainda na segunda parte da coletânea, o artigo de Maria Fernanda Lombardi propõe-se a averiguar o tamanho da influência da teoria política republicana, "fundamentada na virtude dos cidadãos e promotora também dela" sobre o movimento republicano brasileiro, no século XIX. Se denunciar o caráter pouco republicano da República brasileira (caracterizada pelo "primado da invasão do espaço público pelo privado") não representa exatamente uma novidade, ${ }^{5}$ restam dúvidas sobre o papel que a teoria política republicana exerceu sobre o movimento que derrubou a casa monárquica dos Bragança e sobre a razão pela qual uma teoria passível de ser interpretada radicalmente se tornou atraente à elite agrária brasileira.

Lombardi tenta responder às duas questões, apontando, em primeiro lugar, o papel marginal para dizê-lo de modo leve - que o republicanismo teórico desempenhou no movimento: "Aparentemente, não havia uma preocupação com esse conceito de República [entendida como "comunidade política ideal"] por parte da maioria dos envolvidos no movimento republicano", isso a despeito da atuação de personagens mais radicais, como José do Patrocínio e Silva Jardim. Semelhante fracasso normativo da república, por assim dizer, pode ser explicado pela forma como foi conduzida a abolição da escravatura: "o republicanismo de membros mais radicais empobreceu após o treze de maio" (p. 126), já que a abolição fez com que proprietários rurais escravistas se lançassem ao colo do movimento republicano como forma de vingança contra a Monarquia. Em outras palavras, as da autora, "a condução da abolição pela Coroa inviabilizou não só a Monarquia, mas também uma República de caráter mais popular" (p. 126).

Miguel Ángel Rossi, professor da Universidade de Buenos Aires, oferece-nos por sua vez denso artigo no qual questiona a tese - bastante difun- dida entre teóricos e filósofos políticos - de que uma teoria sobre a representação política só teria sido desenvolvida no começo da modernidade, por Thomas Hobbes. Essa tese esquece "a engenharia política da República Romana, e o quanto a modernidade deve, em relação a essa temática, a pensadores como Guilherme de Ockham e Marsílio de Pádua" (p. 143). Para Rossi, as três categorias que ganharam "força inusitada" na teoria política contemporânea - deliberação, representação e decisionismo - não são invenções modernas. Afirmá-lo seria ignorar o papel da deliberação na pólis grega, os germes da representação na jovem República Romana (na instituição dos Tribunos da Plebe), ${ }^{6}$ e a emergência do decisionismo, com Agostinho, que desenvolve os conceitos de livre-arbítrio e de vontade.

$\mathrm{Na}$ terceira parte do livro, o texto de Álvaro de Vita, "Justiça e parcialidade nacional", enfrenta questão teórica espinhosa: da possibilidade teórica de expansão dos princípios de justiça social para a sociedade internacional. Existirão bases teóricas e morais para a defesa de um sistema de justiça distributiva de alcance internacional, ${ }^{7}$ ou "nossos compatriotas têm um direito moral e exigir de nós uma consideração especial por seu bem-estar de modo que os cidadãos de outros estados não têm" (p. 247)? Podemos colocar este dilema em termos de uma oposição entre a defesa da parcialidade nacional e um argumento "liberal-cosmopolita".

$\mathrm{O}$ autor toma o partido da legitimidade de uma justiça distributiva internacional, enfrentando com destreza analítica os argumentos em sentido contrário, que podem ser assim sintetizados: não há algo como uma comunidade internacional, uma vez que não há instituições internacionais nem uma comunidade mundial compartilhada de valores. $\mathrm{O}$ espaço nacional, ao contrário, preencheria estes requisitos: seria uma comunidade compartilhada de valores dentro da qual há acordos sobre princípios e uma identidade comum. O máximo que concedem os "nacionalistas" é que "há formas de interação e de cooperação internacional" (como negá-lo?), mas não uma comunidade no sentido pleno do termo.

Com bem afirma Vita, o problema com este último argumento confunde os planos fático e axiológico, ao apresentar uma objeção de fato ("não 
existem instituiçôes globais justas") como se tratasse de uma objeção de princípio ("não deve haver instituiçôes globais de caráter distributivo, uma vez que na há princípios comuns para sustentá-las”). Se a primeira afirmação dificilmente pode ser contrariada, não há como brandi-la como se significasse o mesmo que a segunda afirmação.

Ademais, argumenta o autor, é empiricamente questionável a crença em que os arranjos redistributivos dos Estados Nacionais sejam precedidos por acordos de princípios e sentimentos de identidade comuns: "Será que estruturas do Estado-nação só surgiram lá onde foram precedidas pela emergência de um consenso normativo dessa natureza?”. É mais plausível, sugere Vita, que instituiçōes comuns tenham precedido significados sociais comuns, e não o contrário (pp. 249-250). Se não é a empatia que explica o surgimento de instituiçóes de justiça distributiva, tampouco é a empatia entre concidadãos que as sustenta e mantém: os modestos arranjos redistributivos implantados no âmbito nacional brasileiro dificilmente podem ser explicados pela solidariedade entre os cidadãos em razão de sentimentos de identidade e de valores compartilhados. Afinal, "Que espécie de identificação empática ou de solidariedade se pode supor que exista, por exemplo, entre os mais ricos das regiōes mais prósperas e os mais pobres das regiōes menos prósperas em um Estado-nação como o brasileiro?” (p. 251). Vita cita então Brian Barry, quem, no âmbito da mesma discussão nos lembra de que mecanismos distributivos não se estabelecem como o resultado da afirmação da nacionalidade e identidade comuns, mas justamente pelo conflito. A emergência de instituições redistributivas costuma resultar da atuação de um partido que procura dividir e contrapor o eleitorado em termos de classe social. Já o discurso da nacionalidade, no mundo real, costuma ser mobilizado com objetivos opostos: "o mais comum é a direita política apelar aos valores da nacionalidade para colocar os interesses da nação acima dos interesses de grupos sócio-econômicos desfavorecidos" (p. 251).

Por fim, há ainda uma forte razão para a defesa de uma justiça redistributiva em escala global: é a existência de um sistema distributivo internacional, ou seja, de um sistema econômico que alcança e integra todo o globo, sistema feito de "práticas" e "arranjos institucionais globais" que "de fato têm efeitos distributivos que contribuem significativamente para a geração de pobreza em escala global e para a existência de vastas desigualdades de oportunidades de vida no mundo" (p. 249).

Já na quarta e última parte do volume, o leitor encontrará um belo e denso texto de Enrique Dussel; e, na linha do "retorno ao direito", menciono brevemente o belo artigo de Werneck Vianna "Americanismo e direito: uma discussão sobre a autocomposição do social”, em que o autor reflete sobre a extroversão do direito, disciplina vista com crescente atenção e interesse pelas ciências sociais; na mesma linha, o panorâmico texto de Andrei Koerner ("Direito e modernização periférica") rende contas sobre o estado da arte e o ponto em que estamos nos estudos constitucionais nos Estados Unidos e no Brasil, especialmente no que se refere às respectivas Cortes Supremas.

À parte alguns problemas tipográficos que podem ser sanados com revisão mais criteriosa e que certamente serão corrigidos numa segunda edição, o livro representa excelente contribuição para o debate teórico no país. Esperamos que este seja apenas o início de um longo caminho, e que a maior difusão da teoria política possa contribuir para tornar o debate político mais informado e substantivo em nossa esfera pública carente de teoria.

\section{Notas}

1 Por outro lado, há notáveis lacunas no processo: não se compreende a razão pela qual um autor como Gerald A. Cohen - responsável por promover importantíssima interlocução entre o marxismo e o liberalismo igualitário rawlsiano - não tenha sido lançado no país até o momento, apenas para citar um exemplo.

2 Philip Pettit, Republicanism: a theory of freedom and government, Nova York, Oxford University Press, 1997.

3 Idem, p. 19.

4 Instituição pela qual o monarca outorgava a um súdito espanhol o direito de explorar o trabalho dos indígenas e de cobrar-lhes tributos, com a contrapartida de evangelizá-los. 
5 Ver, por exemplo, Emília Viotti da Costa, Da Monarquia à República: momentos decisivos, São Paulo, Brasiliense, 1985.

6 Ver a narrativa da criação da instituição dos tribunos da plebe em Tito Lívio, History of Rome, Cambridge, Harvard University Press, 1988, Livro 2, pp. 325-329. Parece difícil compreender esse instituto romano em outros termos que não os da representação política.

7 Entendamos que este problema é abordado aqui do ponto de vista teórico e normativo, independentemente das possibilidades concretas de implementar um sistema internacional de justiça social.

8 O mesmo tema, a saber, a defesa da regulação de desigualdades econômicas por princípios de justiça distributiva no plano internacional, foi posteriormente desenvolvido de forma mais ampla em Álvaro de Vita, O liberalismo igualitário: sociedade democrática e justiça internacional, São Paulo, Martins Fontes, 2008.

\section{JÚLIO CÉSAR CASARIN BARROSO SILVA é doutor em Ciência Política pela Universidade de São Paulo. E-mail: <juliocesarcbs@hotmail.com>.}

